\title{
The Circular Enterprise
}

\author{
Antonella Zucchella*, Sabine Urban ${ }^{* *}$
}

\begin{abstract}
The circular economy challenges business firms to adopt principles of sustainability by closing, narrowing, extending the loop of resources, in order to minimize impact on the planet. Firm embracing circularity principles have to innovate not only products and processes, but primarily models of business. Also they need to include suppliers and customers in their model, as well as any relevant stakeholder, developing eco-systemic business models. The challenge of implementing circular business models encompasses both established and larger organizations and younger ventures (born circular firms).
\end{abstract}

Keywords: Circular Economy; Entrepreneurship; Circular Business Models; Born Circular Firms; Global Markets

\section{The Grand Challenges for the Planet and the Role of Firms}

The so-called "Grand challenges" are confronting humanity and threatening life on our planet. The United Nations have outlined 17 sustainable development goals to be achieved by 2030: "They address the global challenges we face, including those related to poverty, inequality, climate change, environmental degradation, peace and justice" (UN, website). Grand challenges and sustainable development goals (SDG) represent a framework for all the actors involved in sustainable development, policy makers, non-profit organizations, business firms.

In 2009, Lambin wrote a seminal essay on this Journal, inviting scholars and companies to consider alternative models of doing business: "The question is to know whether the capitalist system will be able to evolve toward a business model compatible with the objective of sustainable development, a central preoccupation for the world economy confronted with climatic changes. To the firm, the challenge is formidable: how to conciliate the profitability imperative with the necessity to reduce waste, pollution and carbon emissions? New business models can contribute to amend the capitalist system and to support the objective of sustainable development by decoupling economic growth and environmental destruction" (Lambin, 2009, p. 3).

Following Lambin's invitation, this contribution highlights particularly the role of firms in pursuing environmental goals, together with profitability, and creating shared value among the different stakeholders involved. The specific context of the paper is the circular economy, which represents an alternative model to the linear

\footnotetext{
* Full Professor of Marketing, Pavia University (antonella.zucchella@unipv.it)

${ }^{* *}$ Emeritus Professor, Strasbourg University (ubsabine@gmail.com)
}

Zucchella, A., \& Urban, S. (2020). The Circular Enterprise. Symphonya. Emerging Issues in Management (symphonya.unicusano.it), (1), 62-69. 
economy, traditionally based on supply of material, production and disposal. The linear economic model has depleted the planet resources, while increasing exponentially the problem of waste disposal. Thus, it is no longer sustainable and requires a progressive shift towards a circular economic model, based on extending the life of products, repairing, re-using, upcycling and recycling, sharing and leasing instead of buying. The concept is discussed in Lambin's seminal article as the loop economy: "In a traditional economy, the product life cycle is linear "from cradle to grave". In a loop economy by contrast, this linear life cycle is replaced by a loop "from cradle to a new cradle", by adopting re-using, re-manufacturing and technology-updating strategies and by re-cycling used products and the wastes generated by a particular production process for other productions or for other industries. Repair, reuse, upgrading, remanufacturing, recycling and down cycling are the six main closed-loop principles to keep the gift of good materials and good work moving on to other users and other uses" (Lambin, 2009, p. 7). The Author also suggests that the loop or circular economy can be fruitfully combined with other innovative models like the product-as-service to serve a new model of sustainable capitalism: "The models of a loop economy and of a functional service economy are complementary and propose promising solutions for developing an eco-responsible capitalism" (Lambin, 2009, p. 4).

The circular economy model is described by the European Union as follows: "The circular economy is a model of production and consumption, which involves sharing, leasing, reusing, repairing, refurbishing and recycling existing materials and products as long as possible. In this way, the life cycle of products is extended. In practice, it implies reducing waste to a minimum. When a product reaches the end of its life, its materials are kept within the economy wherever possible. These can be productively used again and again, thereby creating further value" (European Parliament, 2018).

The Ellen McArthur Foundation, one of the main think tanks in the field, proposes the following definition: "A circular economy is based on the principles of designing out waste and pollution, keeping products and materials in use, and regenerating natural systems" (Ellen McArthur Foundation website).

From these definitions, it is clear that business firms have a key role in the circular economy: all the actions and business models mentioned above are developed by firms willing to tackle the shift towards this new economic paradigm. Of course, firms need an enabling institutional framework, capable of supporting this transition. For example, the European Commission has adopted a new Circular Economy Action Plan, as part of the European Green Deal. This Plan will cover "initiatives along the entire life cycle of products, targeting for example their design, promoting circular economy processes, fostering sustainable consumption, and aiming to ensure that the resources used are kept in the EU economy for as long as possible. It introduces legislative and non-legislative measures targeting areas where action at the EU level brings real added value" (European Commission, 2020).

It is reasonable to hypothesize that in a circular economy a major actor of change is represented by circular enterprises. Though literature on the subject is recently blooming, we still need to understand fully what it means for a firm to embrace the circular economy and which is the contribution of the business model to this goal.

Among firms pursuing circular economy principles and models of business, we draw a distinction, based on our recent book (Zucchella \& Urban, 2019): on one side we have long established and often large companies, transitioning towards circularity, while on the other side we have young firms and startups, having 
circularity in their DNA since inception and carriers of radical innovations, particularly in terms of business models. We call the latter cluster of firms "Born circular" enterprises.

Understanding these two groups of firms permits on one side to identify the specific opportunities and barriers to implementation of circularity principles, and - on the other side - highlights the relevance of cooperation among the two categories of players. Young circular ventures are carriers of often disruptive innovations in technologies and markets, but lack managerial and financial resources. Larger established firms usually do possess these resources but lack innovativeness and are constrained by organizational routines and culture, especially when a novel economic paradigm is in sight.

Of particular interest in this contribution is the role of innovation in business models. The circular enterprise creates value for itself and for different stakeholders, including future generations, through a set of business models. These business models are aimed at closing the loop of resources, by extending the life of products, giving new life to products, by recycling and upcycling, optimizing use through sharing, and so on. They represent novel and circular combinations of resources, activities and relationships, targeting customers, users and citizens through a circular value proposition.

\section{The Circular Economy and Its Approaches}

The circular economy is a term coined in 1990 (Pearce \& Turne, 1990) and since then it received increasing attention. However, some key concepts which feed the circular economy idea have been around for some time and certainly before 1990 .

For example, topics like life cycle assessment and cradle to cradle date back to the '70s. Notwithstanding this earlier interest in matters about the sustainability of the actual economic model and the development of approaches aimed at "closing their loop" in the use of increasingly scarce resources, we can observe that the circular economy and related issues gained momentum especially in the last thirty years. This happens from the birth of the term Performance economy in 1986 by Walter R. Stahel (Stahel, 2019) and - on the other hand - the publishing in 1987 of WCED Report on "our common future", which contains a definition of sustainable development. In 1989 both industrial ecology and green economy are brought into the debate. After the mentioned book by Pearce and Turner in 1990, introducing the term circular economy, we can observe the emergence in the following years of the design for sustainability and the more widespread application of cradle to cradle (C2C) principles (McDonough et al., 2010), the Industrial Ecology contribution, the triple bottom line (3BL) concept (Elkington, 1998), biomimicry (Benyus, 1997), the idea of Extended Producer Responsibility (EPR), just to mention some main streams. These conceptualizations have accompanied the growth of the circular economy idea, providing tools and approaches from different perspectives: the circular economy thus progressively evolved into "a social construct which grew out of the sediment layered by many different concepts" (CIRAIG, 2015).

All these approaches give to the circular enterprise idea concrete instruments to put into practice the circularity principles. For example: 
- The triple bottom line indicates the need to pursue contemporarily profit, environmental and social goals. Nowadays increasingly they speak of "purpose" to provide a comprehensive term for the diverse objectives of the firm.

- The cradle to cradle approach provides a way to design products and services, for a zero impact on the planet resources. Products are designed to be fully reusable, re-cyclable and thus close the loops of resources.

- The extended life aims at creating products which can be more easily repaired and last longer, to minimize their impact on the planet and thus extend the loop of resources.

- Industrial ecology provides a framework for developing ecosystems of actors of the circular economy, from private firms and their suppliers and customers to research centers, policy makers, citizens and other organizations.

A major contribution to a more widespread notoriety of the circular economy concept is due to the establishment in 2010 of the Ellen MacArthur Foundation, accompanied in recent years by an increasing interest by think tanks, consulting firms and by the birth of other institutes with similar purposes. The blooming of initiatives in this decade sets a promising avenue for a better development of the circular economy ideas, methods and approaches.

Also policy makers have shown increasing interest in the matter. A case is represented by the Circular Economy legislation adopted by the Chinese government in 2008 , with a cleaner production focus. However, since the '90s different policy makers have adopted measures inspired to the idea of decoupling economic development from natural resources exploitation, without necessarily referring to the idea of a circular economy.

The concept of circular economy has been embraced also at the city level, as for example in the cases of some Dutch cities, Phoenix in the USA, Masdar City in the UAE. The European Union adopted in 2014 a package on the circular economy, but the package has been substituted by the new circular economy plan mentioned in the introduction as part of the European Green Deal.

The interest of policy makers shows increasing commitment towards the implementation of the circular economy in different regions. This implies that regulations tend to evolve more favorably for environmentally sustainable and circular businesses and public financial resources are increasingly made available for circular projects.

\section{The Circular Enterprise}

A number of previous studies has dealt with the idea of making business compatible with sustainable development. Corporate social responsibility is one of the major streams addressing this issue (Carroll, 1999; Lee, 2008) and it has been defined as "business' entryway into Sustainable Development" (CIRAIG, 2015, p. 5). Later on, the triple bottom line conceptualization (Elkington, 1998) reinforced the need for integrating profit objectives with environmental and social issues. The Shared Value perspective offered by Porter and Kramer (2011) also aims at reconciling the capitalistic economy with societal needs. These Authors assume a stance, which is not confined to limits to doing business, but on the contrary, considers the opportunities that a new "sustainable" capitalism can offer to firms. In particular, 
addressing new needs, adopting new technologies and models of business can pave the way to a new wave of innovations and growth.

Increasingly the management literature supported the idea that a sustainable firm goes beyond a mere respect of some standards of good behavior, and requires a deeper re-thinking of their organizations: "The response of firms to sustainable development issues needs to pass through a deep rethinking of the strategic design, encompassing the entire organization, its functions and reshaping its business model" (Zucchella \& Urban, 2014, p. 86).

Zucchella and Urban (2019) analyze in their book a number of cases of established and larger firms in comparison to young and nascent ventures, all characterized by the idea of pursuing the principles of the circular economy.

First, they found that circular firms are never stand-alone organizations, but instead rely on a network. They need to establish strict cooperation with partners in the value chain, but also with consumers, communities and institutions.

Second, the circularity principles embrace much more than manufacturing activities and are extended to service activities and agriculture. Also, they determine the rise of circular service providers and new businesses, which are intended to provide complementary assets and capabilities to other organizations in the system.

Third, the circularity principles often extend beyond "green practices" and embrace social practices. A good example is represented by firms which declare they pursue contemporarily circular economy and solidarity economy principles, for example by employing disadvantaged people in getting jobs. They make a point in underling a key difference between donating to these people and to the non-profit organizations which support them, and employ these people directly, giving a change to "utilize" otherwise wasted human resources. Another example is represented by circular firms, which also make sure that people employed in their company and in their suppliers' premises receive a decent salary and working conditions follow good practices.

Fourth, sometimes also governance models are innovated and bent to the circular economy principles: it is the case for example of the adoption of the benefit company form or similar models, which highlight the pursuing of purpose instead of mere profit maximization.

Finally, the research also permitted to highlight two distinct groups of circular firms: long established and larger firms, which are on the move towards the implementation of circularity principles, and smaller young companies, which are "born circular". It seems plausible that young ventures are at an advantage if compared to established players: the orientation towards a circular economy involves profound transformations in business activities and newly born players have to possibility to design from scratch their circular business, without constraints from existing organizational routines, capabilities and cultures. At the same time, large players can deliver relevance and impact to a circular economy development and can also support the growth of smaller and resources - constrained realities. Also, in innovative and potentially disruptive contexts, large incumbents can benefit from learning through partnerships with new players.

\section{Circular Business Models}

The business model represents a configuration of resources, activities, partnerships and channels, centered around the value proposition offered to the potential 
customers/users. The value proposition can be briefly explained as a "what for whom" statement incorporating a customer insight and the benefit(s) to be delivered to the customer. "In a circular economy project, the value is understood as both economic and social/environmental value, while the "customer" is a more multifaceted construct, spanning from users and buyers to communities and relevant stakeholders of the project" (Zucchella \& Urban, 2019, p. 76).

Circular business models have the purpose - as mentioned before - of reducing the impact of economic activities on the planet - ideally achieving a zero impact. Thus a circular business model in its strictest sense closed the loop of resources. However, the evolution of the literature defines as circular business models those aimed at closing, narrowing, slowing, intensifying and dematerializing loops. This encompasses recycling (closing), efficiency improvements (narrowing), product life extensions (slowing), a more intense utilization (intensifying), and the substitution of products by services and digital solutions (dematerializing) (Geissdoerfer et al., 2018; Rosa et al., 2019). It is not infrequent that circular enterprises adopt combinations of business models. An interesting example is FairPhone: the company is a young firm which embraced since its inception the principles of sustainable development and - in particular - they aim at a fully circular model of business. They manufacture smartphones, which are sustainable because they both respect workers and the planet. Regarding the circular side of their business, they design their phones to be modular and easy to repair and to last longer. Thus they adopt both a repair and an extend life business model. Then they also try to eliminate e-waste: at the end of the phone life, they invite customers to give back to phone, so its components and materials can be recycled or re-used (recycling and upcycling).

Another example is Mud Jeans, a champion of the circular economy. Established in 2013, the Dutch firm sells and rents apparel (primarily jeans): on their platform: the users can rent a pair of jeans for 12 months and then buy or give them back to the firm, to be recycled. We can thus observe the adoption of different models: sharing/renting instead of buying (the product as service business model), recycling and upcycling. Both examples show the need of involving in the business model also suppliers and customers. It is key for circular enterprises to ensure that all suppliers follow similar principles of sustainability and circularity, as well as the engagement of customers is key for the success of the model (Zucchella \& Urban, 2019).

For this reasons, Zucchella and Previtali (2019) discuss the characteristics of the so-called eco-systemic business models, which represent a gap in studies. The literature treats circular business models as tand-alone, with their boundaries represented by the firm's boundaries. At the same time, it is acknowledged that achieving circularity requires a system of interconnected actors. "The relationship between industrial eco-systems and circular business models requires a deeper understanding: while the eco-system provides a "stakeholders" architecture", a system of actors and their relationships, the circular business model (which has mostly been conceived at the single firm level), can encompass this system of actors and provide the "operational and economic architecture" to make the eco-system viable and sustainable also from the financial point of view" (Zucchella \& Previtali, 2019, p. 277).

\section{The Future of Circular Enterprises}


Circular enterprises are blooming around us, as reported by the stories collected in the website of the Ellen McArthur Foundation or those reported in Symbola (2018).

This trend is certainly encouraging and speaks about the increasing commitment of companies towards sustainable development goals and the circular economy principles, in particular. At the same time, we can observe some issues and possible constraints to the development of circular enterprises. First, born circular firms are certainly at an advantage in interpreting in innovative ways the circularity principles: they are young ventures without constraints from existing routines and culture. However, they also find problems in finding resources and bear a substantial risk, because of their innovative value proposition and model of business. Larger and established players - on the other hand - find resistances to change both internally and also in their existing network of partnerships and suppliers. Ideally, these two worlds should establish a cooperation, to cross fertilize each other. For example Enel, with its Open Innovability concept, is incubating innovators in clean energy and related businesses. Enel website (https://openinnovability.enel.com/) declares "we have decided to create a crowdsourcing platform with the capacity to attract and process the most innovative solutions that respond to the main challenges of sustainable development identified in our Group's strategic plan and in the 17 Sustainable Development Goals (SDGs) outlined in the United Nations 2030 Agenda. In three years, openinnovability.com has hosted over 70 challenges, collected thousands of solutions from over 90 countries worldwide, awarded economic prizes and signed collaboration agreements with Italian and international companies, startups, researchers and individuals". The Open Innovability project thus represents a possible benchmark for large companies, which are expected to transition to sustainability and circularity.

A second issue for the development of circular business models is represented by the effective appeal to markets of their innovative value proposition. From this point of view two can be the main obstacles: the first is the acceptance of models which are not usual for the buyer, like for example renting/sharing instead of buying, or the use of recycled materials, particularly in cases like apparel. The second problem is the willingness to pay for sustainable products and services (Zucchella \& Urban, 2019). While most people are aware of the sustainability imperative and agree about SDGs and circularity principles, only a smaller fraction effectively buys sustainable goods and services, and even more so if they cost more. Increasingly behavioral science is called upon to provide answers for changing positively consumers' behaviors (Osbaldiston \& Schott, 2012).

Finally, a third issue is represented by the need to conceive circular business models as eco-systemic, encompassing a variety of actors. In these eco-systems, it is particularly relevant that all the suppliers embrace the circularity principles and align their practices. This may prove particularly difficult when a firm has different tiers of suppliers spread across the world. For example, FairPhone, one of the cases mentioned before, in order to achieve full circularity, is trying to reach and align also third and fourth tier suppliers.

Among the key actors in circular eco-systems, together with customers/users and suppliers, we have policy makers, who may be asked to play an important role in supporting these projects and developing circularity-friendly regulations.

\section{Bibliography}


Benyus, J. M. (1997). Biomimicry. New York: William Morrow.

Carroll, A. B. (1999). Corporate Social Responsibility: Evolution of a Definitional Construct. Business \& Society, 38(3), 268-295.

http:/dx./doi.org/10.1177/000765039903800303

CIRAIG (2015). Circular Economy: A Critical Review of Concepts, Final Report, ESG-UQAM, December.

Elkington, J. (1998). Partnerships from Cannibals with Forks: The Triple Bottom Line of $21^{\text {st }}$ Century Business. Environmental Quality Management, 8(1), 37-51.

Geissdoerfer, M., Morioka, S. N., de Carvalho, M. M., \& Evans, S. (2018). Business Models and Supply Chains for the Circular Economy. Journal of Cleaner Production, 190, 712-721. http://dx.doi.org/10.1016/j.jclepro.2018.04.159

Lambin, J. J. (2009). Capitalism and Sustainable Development. Symphonya. Emerging Issues in Management, (symphonya.unimib.it), (2), 3-9.

http://dx.doi.org/10.4468/2009.2.021ambin

Lee, M. D. P. (2008). A Review of the Theories of Corporate Social Responsibility: Its Evolutionary Path and the Road Ahead. International Journal of Management Reviews, 10(1), 53-73.

http://dx.doi.org/10.1111/j.1468-2370.2007.00226.x

McDonough, W. \& Braungart, M. (2010). Cradle to Cradle: Remaking the Way We Make Things. MacMillan.

Osbaldiston, R., \& Schott, J. P. (2012). Environmental Sustainability and Behavioral Science: Meta-Analysis of Proenvironmental Behavior Experiments. Environment and Behavior, 44(2), 257-299.

http://dx.doi.org/10.1177/0013916511402673

Pearce, D., \& Turner, R. K. (1990). Economics of Natural Resources and the Environment. Harvester Wheatsheaf, London.

Porter, M. E., \& Kramer, M. R. (2011). Creating Shared Value. Harvard Business Review, 89(1/2), 62-77.

Rosa, P., Sassanelli, C., \& Terzi, S. (2019). Towards Circular Business Models: A Systematic Literature Review on Classification Frameworks and Archetypes. Journal of Cleaner Production, 236, 117696. http://dx.doi.org/10.1016/j.jclepro.2019.117696

Stahel, W. R. (2019). Innovation in the Circular and the Performance Economy. Handbook of Sustainable Innovation. Edward Elgar Publishing.

Symbola (2018). 100 Italian Circular Economy Stories. ENEL-Symbola, March.

WCED (World Commission on Environment and Development) (1987). Our Common Future, Oxford University Press.

Zucchella, A., \& Previtali, P. (2019). Circular Business Models for Sustainable Development: A "Waste is Food" Restorative Ecosystem. Business Strategy and the Environment, 28(2), 274-285. http://dx.doi.org/10.1002/bse.2216

Zucchella, A., \& Urban, S. (2014). Futures of the Sustainable Firm: An Evolutionary Perspective. Futures, 63, 86-100.

http://dx.doi.org/10.1016/j.futures.2014.08.003

Zucchella, A., \& Urban, S. (2019). Circular Entrepreneurship. Springer International Publishing. 